\title{
Thyroid Hormone Levels and Its Relationship with Human Chorionic Gonadotropin in Patients with Hydatidiform Mole
}

\author{
Nankali Anisodowleh'1, Keshavarzi Farahnaz' ${ }^{1}$ Jalilian Nasrin ${ }^{*}$, Hematti Maryam², \\ Basami Elaheh $^{3}$ \\ ${ }^{1}$ Maternity Research Center, Department of Obs \& Gyn, Imam Reza Hospital, Kermanshah University of \\ Medical Sciences (KUMS), Kermanshah, Iran \\ ${ }^{2}$ Kermanshah University of Medical Sciences (KUMS), Kermanshah, Iran \\ ${ }^{3}$ Clinical Research Development Unit, Department of Obs \& Gyn, Imam Reza Hospital, Kermanshah University \\ of Medical Sciences(KUMS), Kermanshah, Iran. \\ Email: "njalilian@yahoo.com
}

Received 11 November 2015; accepted 22 January 2016; published 25 January 2016

Copyright (C) 2016 by authors and Scientific Research Publishing Inc.

This work is licensed under the Creative Commons Attribution International License (CC BY).

http://creativecommons.org/licenses/by/4.0/

(c) (i) 0pen Access

\begin{abstract}
Objective: Hydatidiform pregnancy occurs in 1:1000 pregnancies worldwide; incidence is higher in Asian countries. In approximately $\mathbf{5 \%}$ of cases of hydatidiform mole, clinical hyperthyroidism is present. The aim of this study was to examine the relation between HCG level and thyroid function test. Methods: During 5 years (2009-2013) we included 146 cases of molar pregnancies into the study at Imam Reza teaching hospital. The demographic and clinical data as well as serum initial HCG level and thyroid function test (TSH T3 T4) were retrieved and entered into prepared proformas. $p<0.05$ was considered significant. Result: The mean age of patients was 29.31 years; mean of gestational age was 11.71 weeks; mean of gravidity was 2.32; mean of serum BHCG was 3.88E4; mean of $\mathrm{T} 4$ was 11.07 and mean of $\mathrm{T} 3$ was 1.97 . In this study significantly inverse relation was observed between B-HCG and TSH $(p=0.05)$. We also found a significantly direct correlation between B-HCG and T3 $(p=0.01)$ and T4 $(p=0.01)$. Conclusion: We concluded significantly meaningful relationship between BHCG and T3, T4, TSH.
\end{abstract}

\section{Keywords}

Molar Pregnancy, TSH, BHCG, T3, T4, Hyperthyroidism

\footnotetext{
${ }^{*}$ Corresponding author.
}

How to cite this paper: Anisodowleh, N., Farahnaz, K., Nasrin, J., Maryam, H. and Elaheh, B. (2016) Thyroid Hormone Levels and Its Relationship with Human Chorionic Gonadotropin in Patients with Hydatidiform Mole. Open Journal of Obstetrics and Gynecology, 6, 56-63. http://dx.doi.org/10.4236/ojog.2016.61007 


\section{Introduction}

Hydatidiform pregnancy occurs in 1:1000 pregnancies worldwide; incidence is higher in Asian countries [1] [2], Hyperthyroidism is rare complication of molar pregnancy. Thyroid storm occurs even less frequently [3]. Prevalence of hyperthyroidism during complete molar pregnancy is as high as 7\% [1]. Thyroid hyper function in molar pregnancy is attributed to excess of human chorionic gonadotropin which has a weak intrinsic thyroid stimulating activity and molar thyrotrophic hormone, differing from Human Chorionic Gonadotropin (HCG) by being larger in molecular size and longer in duration of action [4] clinical hyperthyroidism because trophoblastic disease is cured by evacuation of molar tissue [5]-[8].

The severity of trophoblastic disease-associated hyperthyroidism can vary from clinically asymptomatic elevations of thyroid hormones to life threatening thyrotoxicosis [9]. Studies indicate the analogy between HCG and thyrotrophic hormone (TSH), as well as among their receptors. The high levels of HCG seen in molar pregnancy may cause secondary hyperthyroidism [10]. In approximately 5\% of cases of hydatidiform mole, clinical hyperthyroidism is present [11] and occasionally severe thyrotoxicosis may develop [12] [13]. The association between elevated HCG and TSH concentration during pregnancy has been known for many years [14] [15]. Numerous studies have documented the thyrotrophic effect of HCG [14] [16] [17]. It has been demonstrated that HCG can bind TSH receptors and suppress TSH production [18]. The aim of this study was to examine the relation between HCG level and thyroid function test (thyroid hormone TSH T3 T4) in patients with the diagnosis of molar pregnancies.

\section{Material and Methods}

This was a retrospective analytic descriptive study carried out on the cases of molar pregnancies who admitted at the department of gynecology in Imam Reza teaching hospital study during 5 years (2009-2013). It was approved by Imam Reza Hospital Clinical Research development unit. Molar pregnancies were diagnosed based on sonographic findings and histological studies. Those with incomplete molar pregnancy and choriocarcinoma excluded from the study. Medical records were reviewed for each subject to establish the subjects clinical thyroid status and document the presence of molar pregnancy. The demographic and clinical data as well as serum initial HCG level and thyroid function test (TSH T3 T4) were retrieved from Patient records and entered into prepared proformas. In 146 registered the patients with hydatidiform mole HCG in blood and thyroid function test was analyzed in our institute. TSH level (0.35 - $6.5 \mathrm{MIU} / \mathrm{ml})$ was considered normal. Normal T4 level was considered 4.8 - $11.6 \mu \mathrm{g} / \mathrm{dl}$. Normal T3 level was considered 0.6 - $2.1 \mathrm{ng} / \mathrm{ml}$. Minimum sample size with confidence interval $95 \%$ and power of $80 \%$ was considered 119 cases. But we included all the patients during our study period (146 cases). SPSS version 20 was used for statistical analysis. To compare the relation between thyroid hormones and HCG Pearson or Spearman correlation was used. $\mathrm{p}<0.05$ was considered significant.

\section{Results}

67 cases of 155 study group (43\%) were 25 - 34 years old and 31\% were 15 - 24 years old and 38\% were more than 35 years old. Regarding gravidity near to $80 \%$ of patients had gravidity one and two. In our study most of patients had subclinical hyperthyroidism 76 cases (49\%) and no patients had clinical hyperthyroidism, and 79 cases (51\%) were euthyroidism. The basic characteristics are shown in Table 1.

25 patients of 155 cases had B-HCG $<10,000$ when they admitted, 40 patients had B-HCG = 10,000, 23 patients had B-HCG between 10,000 - 40,000, 10 patients had B-HCG between 40,000 - 100,000, 34 patients had B-HCG $=100,000$, 5 patients had B-HCG > 100,000. 65 cases (41.9\%) of 155 population study had B-HCG levels up to 10,000, and 90 cases (58.1\%) had B-HCG levels more than 10,000. Table 2 shows frequency of normal and abnormal levels of TSH, T4 and T3 in population study.

In this study the most common presenting symptom was vaginal bleeding, occurring in 81 out of 155 (52\%). Lower abdominal pain was reported in 21 out of 155 cases (13\%). Among 155 cases of molar pregnancy 32 cases was recognized just after doing abdominal sonography for prenatal care and they were asymptomatic (Table 3).

In this study significantly inverse relation was observed between B-HCG and TSH $(p=0.05)$. We also found a significantly direct correlation between B-HCG and T3 $(p=0.01)$ and T4 $(p=0.01)$ (Figure 1).

Mean of B-HCG level in subclinical hyperthyroidism group (76 cases) was 50,000 and in 79 cases without subclinical hyperthyroidism was 20,000, which shows a higher level with subclinical hyperthyroidism. 


\section{Discussion}

Hydatidiform mole is the most common form of gestational trophoblastic disease that originates from the placenta and includes complete and partial site trophoblastic tumors [19]. Clinical hyperthyroidism is relatively common, occurring in about 1 in 100 pregnant woman. This is explained by the similarity of the $\alpha$-subunit of HCG to TSH [20]-[23]. Thyroid storm although rare has a mortality rate as high as 15\% [24]. Subclinical hyper-

Table 1. Basic demographic characteristics of patients.

\begin{tabular}{cccccccc}
\hline & $\begin{array}{c}\text { Age } \\
\text { (year) }\end{array}$ & $\begin{array}{c}\text { gestational age } \\
\text { (week) }\end{array}$ & $\begin{array}{c}\text { Gravidity } \\
\text { (NO) }\end{array}$ & $\begin{array}{c}\text { B-HCG } \\
\text { (IU/L) }\end{array}$ & $\begin{array}{c}\text { TSH } \\
(\mathbf{M I U} / \mathbf{m l})\end{array}$ & $\begin{array}{c}\text { T4 } \\
(\boldsymbol{\mu} / \mathbf{d l})\end{array}$ & $\begin{array}{c}\text { T3 } \\
(\mathbf{n g} / \mathbf{m l})\end{array}$ \\
\hline Mean & 29.31 & 11.71 & 2.33 & $3.88 E 4$ & 1.42 & 11.07 & $\mathbf{1 . 9 7}$ \\
\hline
\end{tabular}

Table 2. Levels of TSH, T4 and T3 in patients.

\begin{tabular}{cccc}
\hline & $\begin{array}{c}\text { Number of patients with normal } \\
\text { levels }\end{array}$ & $\begin{array}{c}\text { Number of patients with less than } \\
\text { normal levels }\end{array}$ & $\begin{array}{c}\text { Number of patients with more than } \\
\text { normal levels }\end{array}$ \\
\hline TSH & $104(67 \%)$ & $42(27 \%)$ & $9(6 \%)$ \\
T4 & $93(60 \%)$ & $3(1.9 \%)$ & $59(38.1 \%)$ \\
T3 & $110(71 \%)$ & - & $45(29 \%)$ \\
\hline
\end{tabular}

Table 3. The common sign and symptom of patients with molar pregnancies.

\begin{tabular}{ccccc} 
& Vaginal bleeding & Abdominal pain & No symptom & Other symptoms \\
\hline $\begin{array}{c}\text { Number } \\
\text { (percent) }\end{array}$ & 81 & 21 & 32 & $\mathbf{2 1}$ \\
& $(52 \%)$ & $(13 \%)$ & $(22 \%)$ & $(\mathbf{1 3 \% )}$ \\
\hline
\end{tabular}

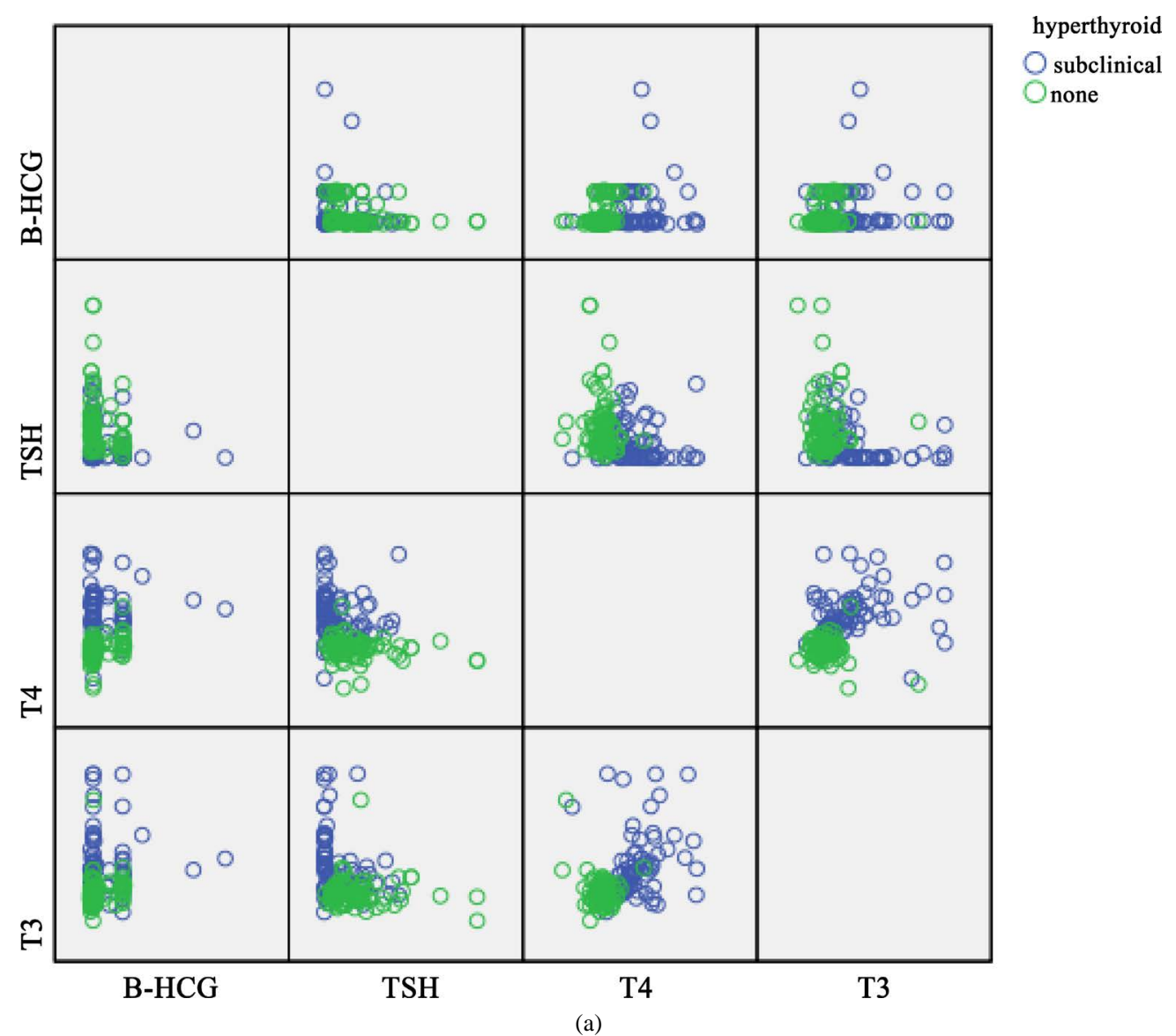


N. Anisodowleh et al.

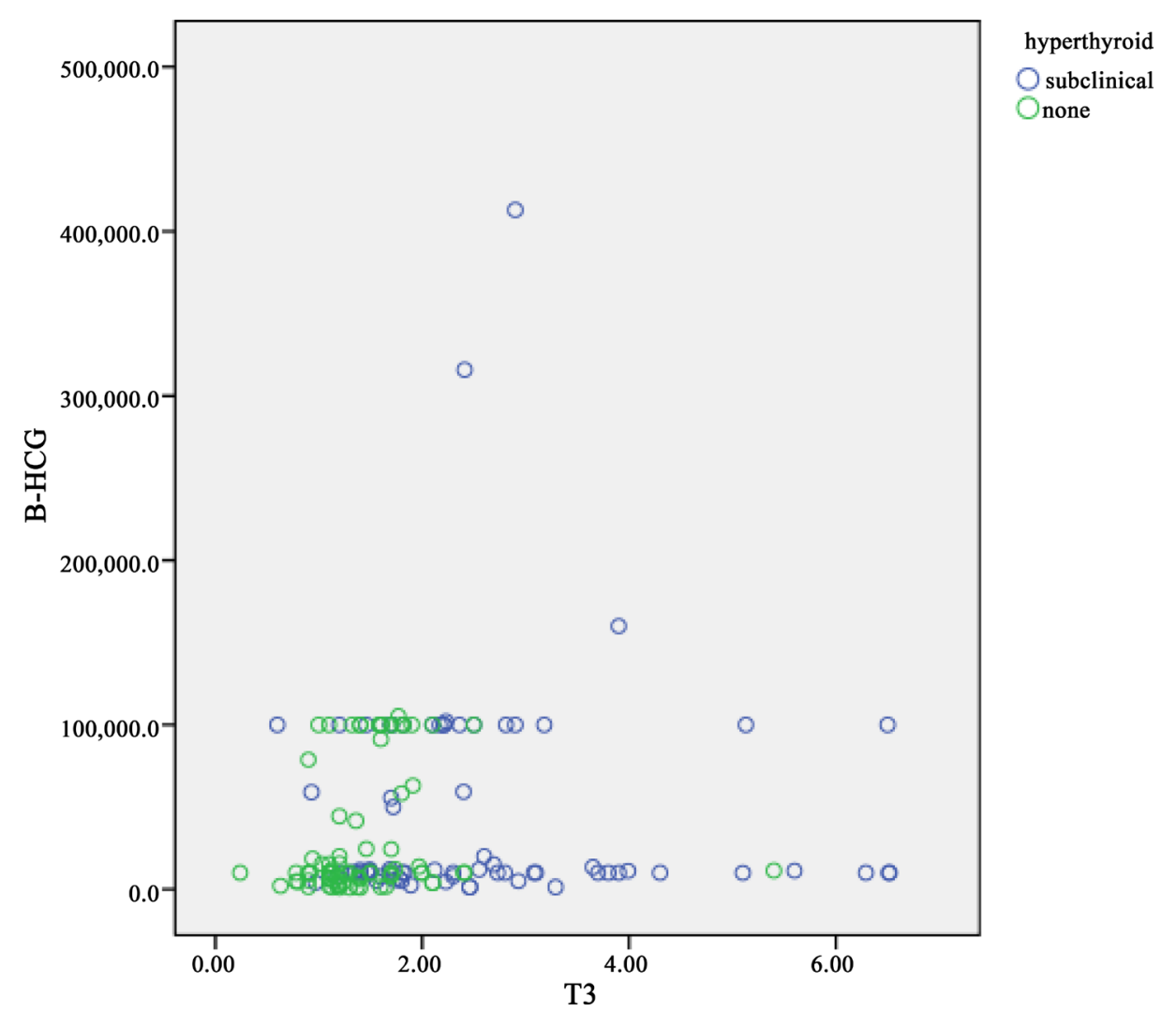

(b)

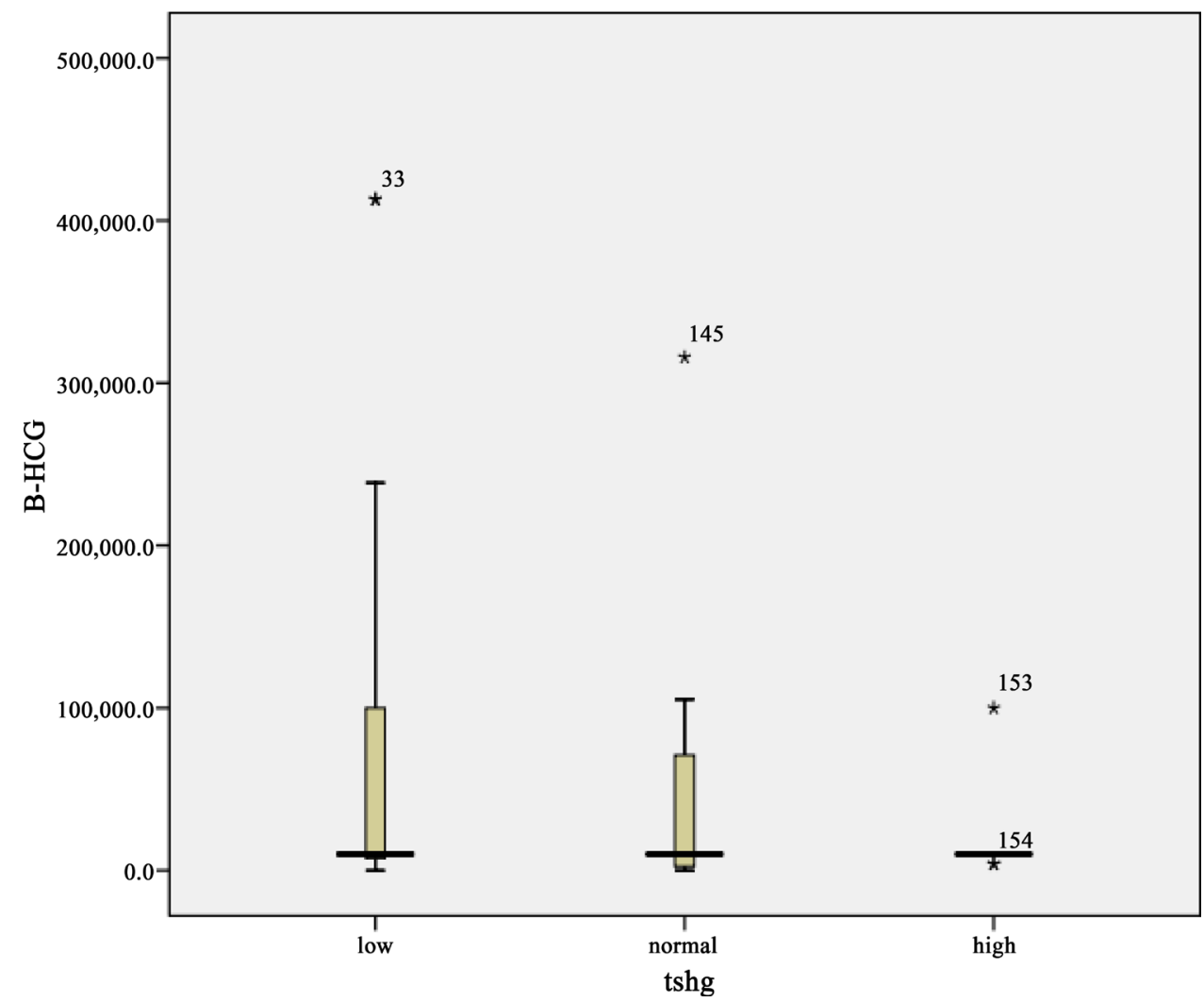

(c) 


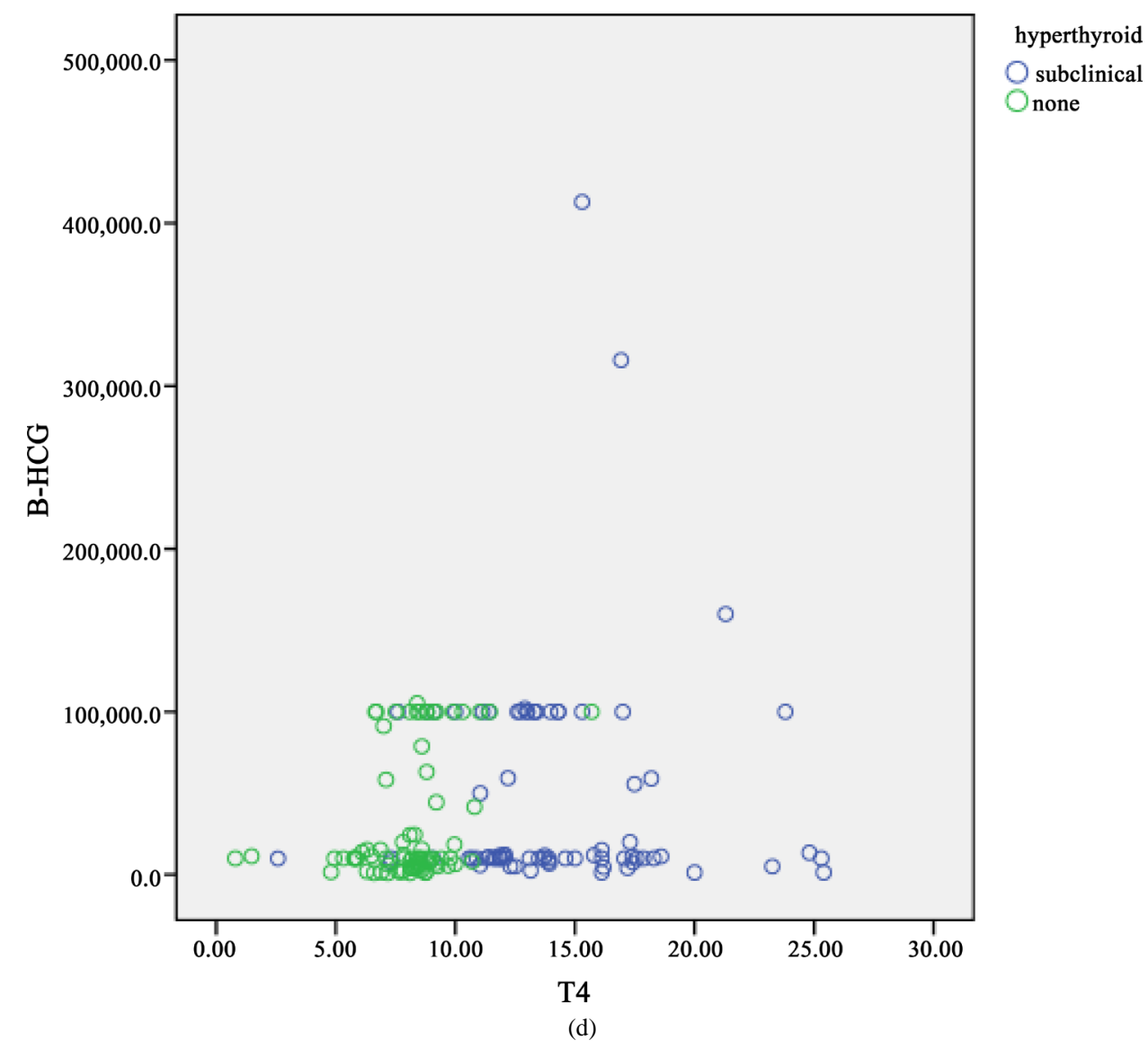

Figure 1. Relation between the hormone levels BHCG, TSH, T4 and T3.

thyroidism is well documented in pregnancy. At the time of peak HCG levels in normal pregnancy, serum TSH falls and bears a mirror image to the HCG peak. This fall in TSH suggests that it is HCG that causes increased secretion of T3 and T4 [25]. When there are clinical features of thyrotoxicosis, as in some cases of hyperemesis gravidum, anti-thyroid treatment may be given, but is rarely required beyond 22 weeks gestation.

Human chorionic gonadotrophin is a glycoprotein composed of $\alpha$ and $\beta$ subunits. The $\alpha$ subunit is almost identical to that found in TSH, luteinising hormone (LH) and follicle-stimulating hormone [25]. The subunit consists of a 92-amino-acid chain containing two nitrogen-linked oligosaccharide side chains. In vitro testing has shown low-affinity cross-reactivity between these hormones [25] [26].

Thyriod-stimulating activity in serum of normal pregnant women shows a significant correlation with levels of serum HCG levels. It is likely that the thyrotrophic activity of HCG during first trimester peak secretion overrides the normal operation of the hypothalamic-pituitary-thyroid feedback system [27]. An association has been reported in certain pathologies of pregnancy, where there is increase in HCG, as in hyperemesis gravidarum, with an increase in thyroid function [28]. In some cases, the gestational trophoblastic disease is complicated with hyper thyroidism. This is believed to occur because of molecular mimicry between HCG and TSH causing cross-reactivity of the molecule of HCG with the TSH receptor. Treating gestational trophoblastic disease normalizes the HCG levels and hyperthyroidism is resolved [29].

The aim of this study was to explore the relation between HCG level with TSH, T3 and T4 in patients with molar pregnancies. HCG shares a common $\alpha$-subunit with TSH, possessed thyroid stimulating activity [30]. Lack wood et al. reported that HCG concentration higher than 400,000 IU/L suppresses TSH level and most patients with HCG higher than 200,000 IU/L lack overt hyperthyroid syndrome [31]. In the present study no patient had clinical hyperthyroid syndrome. This may be due to less HCG level than 200,000 IU/L. But among 76 patients with subclinical thyroid syndrome the mean serum HCG level was 50,000 and in those without subclinical hyperthyroid syndrome was 20,000 which shows a correlation between HCG level and subclinical hyper- 
thyroid syndrome. The HCG levels in present study ranged from 20,000 - 50,000 MIU/L and there is a significantly inverse correlation between the HCG and TSH levels $(\mathrm{p}=0.05)$. Correlation between HCG and T3 was also significant and directly $(\mathrm{p}=0.01)$ and there was direct correlation between HCG level and serume T4 level $(\mathrm{p}=0.01)$. We found higher HCG level in subclinical hyperthyroid syndrome group than in normal group (50,000 versus 20,000 MIU/L).

Lindhome and flan [32] from Sweden have reported on 75 patients with complete mole and 60 with partial moles. In the complete mole group the mean gestational age at the time of sonography was 12.4 weeks which is near to the present study 11.71 weeks. In their study $77 \%$ of patients had vaginal bleeding. In the present study also the most common symptoms was vaginal bleeding 52\% (81 cases). Pain was observed in $13 \%$ (21 cases) of our patients versus $23 \%$ in Lindhome study. In the present study $22 \%$ (32 cases) had no symptom but in Lindhome study 12 patients had experience no symptoms. This may be due to early request for doing ultera sonoghraphy. In view of the controversy regarding the role of human chorionic gonadotropin as the stimulator of thyroid function in patients with trophoblastic tumors, especially hydatidiform mole, we concluded that relationship between HCG and T4 and T3 was direct and meaningful but relationship between HCG and TSH was inverse and meaningful. Regarding this syndrom, Amir [33] found a weakly positive correlation ( $\mathrm{p}<0.05, \mathrm{r}<0.35, \mathrm{n}=47$ ) between the serum human chorionic gonadotropin levels and serum total thyroxine concentrations. However he found no correlation between HCG levels and free thyroxine index values $(p>0.05, r=0.32, n=34)$. Also in that study there was no correlation between serum HCG levels and either serum total 3,5,3'-triiodthyronine concentrations ( $\mathrm{p}>0.1, \mathrm{r}=0.32, \mathrm{n}=17)$. This is against our study which showed a meaningful relationship. The present study support the premise that human chorionic gonadotropin per se is the thyroid stimulator of molar pregnancy.

\section{Conclusion}

We concluded significantly meaningful relationship between BHCG and T3, T4, TSH. Thyroid function tests should be mandatory in all women with hydatidiform mole and these women should be stabilized with $\beta$ blockers and antithyroid medication prior to induction of anesthesia for their surgical evacuation. Vigilant monitoring and intensive care should be extended into the postoperative period because there is a likelihood of occurrence of cardiopulmonary complications, thyroid storm, and disseminated intravascular coagulation.

\section{Acknowledgements}

This work was performed in partial fulfillment of the requirements for Ph.D., of Elaheh Basami.

\section{Conflict of Interests}

The authors declare that there is no conflict of interests regarding the publication of this paper.

\section{References}

[1] Shapter, A.P. and McLellan, R. (2001) Gestational Trophoblastic Disease. Obstetrics and Gynecology Clinics of North America, 28, 805-817. http://dx.doi.org/10.1016/S0889-8545(05)70237-0

[2] Altieri, A., Franceschi, S., Ferlay, J., Smith, J. and La Vacchia, C. (2003) Epidemiology and Aetiology of Gestational Trophobalastic Diseases. Lancet Oncology, 4, 670-678. http://dx.doi.org/10.1016/S1470-2045(03)01245-2

[3] Moskovitz, J.B. and Bond, M.C. (2010) Molar Pregnancy-Induced Thyroid Storm. Journal of Emergency Medicine, 38, 71-76. http://dx.doi.org/10.1016/j.jemermed.2009.08.053

[4] Hershman, J.M. (1992) Role of Human Chorionic Gonadotropin as a Thyroid Stimulator. Journal of Clinical Endocrinology \& Metabolism, 74, 258-259.

[5] Kato, K., Mostafa, M.H., Mann, K., Schindler, A.E. and Hoermann, R. (2004) The Human Chorionic Gonadotropin Molecule from Patients with Trophoblastic Diseases Has a High Thyrotropic Activity But Is Less Active in the Ovary. Gynecological Endocrinology, 18, 269-277. http://dx.doi.org/10.1080/09513590410001667247

[6] Hershman, J.M. (1999) Human Chorionic Gonadotropin and the Thyroid: Hyperemesis Gravidarum and Trophoblastic Tumors. Thyroid, 9, 653-657. http://dx.doi.org/10.1089/thy.1999.9.653

[7] Misra, M., Levitsky, L.L. and Lee, M.M. (2002) Transient Hyperthyroidism in an Adolescent with Hydatidiform Mole. Journal of Pediatrics, 140, 362-366. http://dx.doi.org/10.1067/mpd.2002.120514 
[8] Nandini, D., Sarita, F., Uday, A. and Hemalata, I. (2009) Hydatidiform Mole with Hyperthyroidism-Perioperative Challenges. Journal of Obstetrics and Gynecology of India, 59, 356-357.

[9] Struthmann, L., Günthner-Biller, M., Bergauer, F., Friese, K. and Mylonas, J. (2009) Complete Hydatidiform Mole in a Perimenopausal Woman with a Subsequent Severe Thyriotoxicosis. Archives of Gynecology and Obstetrics, 279, 411413. http://dx.doi.org/10.1007/s00404-008-0734-0

[10] de Almeida, C.E., Curi, E.F., de Almeida, C.R. and Vieira, D.F. (2011) Thyrotoxic Crisis Associated with Gestational Trophoblastic Disease. Revista Brasileira de Anestesiologia, 61, 604-609. http://dx.doi.org/10.1016/s0034-7094(11)70071-x

[11] Berkowitz, R.S., Goldstein, D.P., DuBeshter, B.E., et al. (1987) Management of Complete Molar Pregnancy. Journal of Reproductive Medicine, 32, 634-639.

[12] Itzkowic, D. (1976) Hydatidiform Mole and Thyrotoxicosis. A Case Report. British Journal of Obstetrics and Gynaecology, 83, 86-89. http://dx.doi.org/10.1111/j.1471-0528.1976.tb00736.x

[13] Hershman, J.M. and Higgins, H.P. (1971) Hydatidiform Mole: A Cause of Clinical Hyperthyroidism. New England Journal of Medicine, 284, 573-577. http://dx.doi.org/10.1056/NEJM197103182841103

[14] Guillaume, J., Schussler, G.C. and Goldman, J. (1985) Components of the Total Serum Thyroid Hormone Concentrations during Pregnancy: High Free Thyroxine and Blunted Thyrotropin (TSH) Response to TSH-Releasing Hormone in the First Trimester. Journal of Clinical Endocrinology \& Metabolism, 60, 678-684. http://dx.doi.org/10.1210/jcem-60-4-678

[15] Glinoer, D., de Nayer, P., Bourdoux, P., Lemone, M., Robyn, C., van Steirteghem, A., Kinthaert, J. and Lejeune, B. (1990) Regulation of Maternal Thyroid during Pregnancy. Journal of Clinical Endocrinology \& Metabolism, 71, 276287. http://dx.doi.org/10.1210/jcem-71-2-276

[16] Goodwin, T.M. and Hershman, J.M. (1997) Hyperthyroidism Due to Inappropriate Production of Human Chorionic Gonadotropin. Clinical Obstetrics \& Gynaecology, 40, 32-44. http://dx.doi.org/10.1097/00003081-199703000-00006

[17] Davies, T.F. and Platzer, M. (1986) hCG-Induced TSH Receptor Activationand Growth Acceleration in FRTL-5 Thyroid Cells. Endocrinology, 118, 2149-2151. http://dx.doi.org/10.1210/endo-118-5-2149

[18] Kosugi, S. and Mori, T. (1995) TSH Receptor and LH Receptor. Endocrine Journal, 42, 587-606. http://dx.doi.org/10.1507/endocrj.42.587

[19] Erturk, E., Bostan, H., Geze, S., Saracoglu, S., Erciyes, N. and Eroglu, A. (2007) Total Intravenous Anesthesia for Evacuation of a Hydatidiform Mole and Termination of Pregnancy in a Patient with Thyrotoxicosis. International Journal of Obstetric Anesthesia, 16, 363-366.

[20] Hershman, J.M., Lee, H.Y., Sugawara, M., et al. (1988) Human Chorionic Gonadotropin Stimulates Iodide Uptake, Adenylate Cyclase, and Deoxyribonucleic Acid Synthesis in Cultured Rat Thyroid Cells. Journal of Clinical Endocrinology \& Metabolism, 67, 74-79. http://dx.doi.org/10.1210/jcem-67-1-74

[21] Goodwin, T.M. and Hershman, J.M. (1997) Hyperthyroidism Due to Inappropriate Production of Human Chorionic Gonadotropin. Clinical Obstetrics and Gynecology, 40, 32-44. http://dx.doi.org/10.1097/00003081-199703000-00006

[22] Fantz, C.R., Dagogo-Jack, S., Ladenson, J.H. and Gronowski, A.M. (1999) Thyroid Function during Pregnancy. Clinical Chemistry, 45, 2250-2258.

[23] Amir, S.M., Endo, K., Osathanondh, R. and Ingbar, S.H. (1985) Divergent Responses by Human and Mouse Thyroids to Human Chorionic Gonadotropin in Vitro. Molecular and Cellular Endocrinology, 39, 31-37. http://dx.doi.org/10.1016/0303-7207(85)90089-9

[24] Froeschl, M., Haddad, H., Commons, A.S. and Veinot, J.P. (2005) Thyrotoxicosis: An Uncommon Cause of Heart Failure. Cardiovascular Pathology, 14, 24-27. http://dx.doi.org/10.1016/j.carpath.2004.11.003

[25] Hershman, J.M. (2004) Physiological and Pathological Aspects of the Effects of Human Chorionic Gonadotropin on the Thyroid. Best Practice \& Research: Clinical Endocrinology \& Metabolism, 18, 249-265. http://dx.doi.org/10.1016/j.beem.2004.03.010

[26] Vaitukaitis, J.L. (1977) Human Chorionic Gonadotropin-A Hormone Secreted for Many Reasons. The New England Journal of Medicine, 301, 324-326.

[27] Hershman, J.M. (2004) Physiological and Pathological Aspects of the Effects of Human Chorionic Gonadotropin on the Thyroid. Beast Practice \& Research Clinical Endocrinology \& Netabolism, 18, 249-265. http://dx.doi.org/10.1016/j.beem.2004.03.010

[28] Verbeg, M.F.G., Gillott, D.J., AL-Fardan, N. and Grudzinskas, J.G. (2005) Hyperemesis Gravidarum, a Literature Review. Human Reproduction Update, 11, 527-539. http://dx.doi.org/10.1093/humupd/dmi021

[29] Walkington, L., Webster, J., Hancock, B.W., Everard, J. and Coleman, R.E. (2011) Hyperthyroidism and Human Chorionic Gonadotrophin Production in Gestational Trophoblastic Disease. British Journal of Cancer, 104, 1665-1669. 
[30] Burrow, G.N. (1993) Thyroid Function and Hyperfunction during Gestation. Endocrine Reviews, 14, 194-202. http://dx.doi.org/10.1210/edrv-14-2-194

[31] Lockwood, C.M., Grenache, D.G. and Gronowski, A.M. (2009) Serum Human Chorionic Gonadotropin Concentrations Greater than 400,000 IU/L Are Invariably Associated with Suppressed Serum Thyrotropin Concentrations. Thyroid, 19, 863-868. http://dx.doi.org/10.1089/thy.2009.0079

[32] Lindholm, H. and Flam, F. (1999) The Diagnosis of Molar Pregnancy by Sonography and Gross Morphology. Acta Obstetricia et Gynecologica Scandinavica, 78, 6-9.

[33] Amir, S.M., Osathanondh, R., Berkowitz, R.S. and Goldstein, D.P. (1984) Human Chorionic Gonadotropin and Thyroid Function in Patients with Hydatidiform Mole. American Journal of Obstetrics and Gynecology, 150, 723-728. 